\title{
DEVELOPMENT AND VALIDATION OF A DISSOLUTION TEST FOR PRIMAQUINE/POLYETHYLENE OXIDE MATRIX TABLETS
}

\author{
Ariane P. Cruz, Charise D. Bertol, Fábio S. Murakami, Rafael N. Pereira, Bruno R. Valente e Marcos A. S. Silva \\ Departamento de Ciências Farmacêuticas, Centro de Ciências da Saúde, Universidade Federal de Santa Catarina, Campus \\ Universitário, 88040-900 Florianópolis - SC, Brasil \\ Letícia S. Koester* \\ Departamento de Produção e Controle de Medicamentos, Faculdade de Farmácia, Universidade Federal do Rio Grande do Sul, \\ Av. Ipiranga, 2752, 90610-000 Porto Alegre - RS, Brasil
}

Recebido em 16/5/12; aceito em 12/10/12; publicado na web em 21/2/13

\begin{abstract}
A simple, precise, specific, repeatable and discriminating dissolution test for primaquine (PQ) matrix tablets was developed and validated according to ICH and FDA guidelines. Two UV assaying methods were validated for determination of PQ released in 0.1 M hydrochloric acid and water media. Both methods were linear $\left(\mathrm{R}^{2}>0.999\right)$, precise (R.S.D.<1.87\%) and accurate $(97.65-99.97 \%)$. Dissolution efficiency (69-88\%) and equivalence of formulations ( 2 2) was assessed in different media and apparatuses (basket/100 rpm and paddle/50 rpm) tested. Discriminating condition was $900 \mathrm{~mL}$ aqueous medium, basket at $100 \mathrm{rpm}$ and sampling times at 1,4 and 8 h. Repeatability (R.S.D. $<2.71 \%$ ) and intermediate precision (R.S.D. $<2.06 \%$ ) of dissolution method were satisfactory.
\end{abstract}

Keywords: dissolution; primaquine; matrix tablets.

\section{INTRODUCTION}

Malaria is a tropical disease, largely confined to underdeveloped regions of the globe, which has been traditionally neglected by pharmaceutical industries yet represents a serious world health problem. ${ }^{1,2}$ Primaquine (PQ) is effective against the liver stages of all types of malaria parasites and is used to prevent relapses of malaria and for prophylaxis of individuals returning from malaria affected areas..$^{2-4}$ $\mathrm{PQ}$ is the drug of choice for the radical cure of Plasmodium vivax and P. ovale malaria, although has serious dose-dependent side effects. ${ }^{5}$ The long treatment time with PQ can cause poor patient compliance and lead to periods of sub-therapeutic concentration in plasma, promoting the development of drug resistance ${ }^{6}$ Baird and Hoffman confirmed that there is widespread resistance to PQ therapy, whose dosage is $15 \mathrm{mg}$ base daily for 14 days. ${ }^{4}$ On the other hand, clinical trials of $30 \mathrm{mg} /$ day PQ base had protective efficacy mainly against $P$. falciparum and $P$. vivax. After a $15 \mathrm{mg}$ oral dose of $\mathrm{PQ}$, a mean peak plasma concentration of $65 \mathrm{ng} / \mathrm{mL}$ is achieved within $1-2 \mathrm{~h}$. The drug is rapidly excreted in urine, with a plasma half-life of $4.4 \mathrm{~h} .^{7}$ Due to its short biological half-life and adverse effects, PQ seems to be an ideal candidate for extended release tablets.

Consequently, the development of $\mathrm{PQ} /$ polyethylene oxide matrix tablets is under investigation by our research group aimed at improving treatment efficacy and reducing the limitations of existing therapies. ${ }^{8-10}$ Polyethylene oxide (PEO) was the hydrophilic polymer chosen due to its non-toxicity, nonionic nature and acceptable compatibility. ${ }^{11}$ In vivo data has demonstrated that total PQ exposure in beagle dogs was 2.2 times higher (area under curve of 12193 versus $5678 \mathrm{ng} \mathrm{h} / \mathrm{mL}$ ) with the matrix extended-release tablets compared with the immediate-release tablets. ${ }^{12}$

The dissolution procedure is currently used for development and optimization of drug formulations and dissolution profile comparisons. It must be appropriately discriminating, capable of distinguishing significant changes in quality, composition or manufacturing process of the product that might be expected to affect

*e-mail: leticia.koester@ufrgs.br in vivo performance. ${ }^{13,14} \mathrm{PQ}$ is commonly found in the market as immediate release tablets. There is no method defined for dissolution testing of extended-release tablets. The creative use of dissolution techniques can speed up the initial stages of formulation development, particularly in the case of extended-release products, enabling prompt identification of potential problems in drug release rate. ${ }^{15} \mathrm{~A}$ dissolution test with good precision, for example, makes it possible to efficiently compare different alternative formulation candidates to select the dosage form with the most suitable and reproducible drug release profile. ${ }^{15}$ In this context, the aim of the present work was to develop and validate an appropriate dissolution test for PQ matrix tablets according to current $\mathrm{ICH}^{16}$ and $\mathrm{FDA}^{17}$ guidelines.

\section{EXPERIMENTAL}

\section{Chemicals and reagents}

PQ reference standard was purchased from U.S. PharmacopoeiaRockville (USA) and raw material was donated by Fundação Oswaldo Cruz /Far-Manguinhos. Polyethylene oxide (PEO) of molecular weight $\left(M_{\mathrm{w}}\right)$ of $4 \times 10^{6}$ and $8 \times 10^{6} \mathrm{Da}$ (Sigma Aldrich) was used as the hydrophilic polymer. The other excipients were microcrystalline cellulose (Avicel ${ }^{\circledR} \mathrm{PH}-102$; Blanver), colloidal silicon dioxide (Aerosil ${ }^{\circledR}$, Galena), talc (Charles B Chrystal Co., Inc.) and sodium stearyl fumarate (Pruv/Penwest Pharmaceuticals). Ultrapure water was obtained from a Milli- ${ }^{\circledR}$ apparatus, methanol and acetonitrile HPLC grade were purchased from Vetec (Brazil) and perchloric acid was of analytical reagent grade. Monobasic potassium phosphate, sodium hydroxide and hydrochloric acid were obtained from Nuclear (Brazil). Buffer solutions were prepared according to USP $30 .{ }^{13}$

\section{PQ/PEO matrix tablets}

Four formulations named F30P4, F30P8, F60P4 and F60P8 were prepared by directly compressing physical mixtures of the drug, polymer and excipients, maintaining a total mass of $175 \mathrm{mg}$ (Table 1). Tablet hardness was kept constant at $7 \pm 0.5 \mathrm{Kgf}(\mathrm{n}=10)$ and 
there was no statistically significant difference among the weight of tablets $(174.4 \pm 2.1 \mathrm{mg} ; \mathrm{p}>0.05)$ or drug content values $(52.7 \pm 1.5$ mg; $\mathrm{p}>0.05)$.

Table 1. Composition of matrix formulations

\begin{tabular}{lcccc}
\hline Components $(\mathrm{mg})$ & $\mathrm{F} 30 \mathrm{P} 4$ & $\mathrm{~F} 30 \mathrm{P} 8$ & $\mathrm{~F} 60 \mathrm{P} 4$ & $\mathrm{~F} 60 \mathrm{P} 8$ \\
\hline Primaquine Phosphate $*$ & 52.60 & 52.60 & 52.60 & 52.60 \\
PEO $_{\mathrm{w}} 4 \times 10^{6}$ & 52.50 & 0 & 105.00 & 0 \\
PEO M $_{\mathrm{w}} 8 \times 10^{6}$ & 0 & 52.50 & 0 & 105.00 \\
Microcrystalline cellulose & 63.77 & 63.77 & 8.64 & 8.64 \\
Colloidal silicon dioxide & 0.88 & 0.88 & 0.88 & 0.88 \\
Talc & 5.25 & 5.25 & 5.25 & 5.25 \\
Sodium stearyl fumarate & 0 & 0 & 2.63 & 2.63 \\
\hline
\end{tabular}

* Corresponding to $30 \mathrm{mg}$ primaquine base.

\section{Instrumentation and analytical conditions}

The dissolution tests were performed on a VK 7000 multi-bath $(n=6)$ dissolution tester (Varian, USA), in accordance with USP general methods. ${ }^{13}$

UV analyses were performed on a UV-Vis Spectrophotometer (Cary-50, Varian, USA) using $1 \mathrm{~cm}$ quartz cells. The blanks used were water for UV Method I, and 0.1 M hydrochloride acid for UV Method II.

The HPLC analysis was performed on a Shimadzu LC-10A system (Kyoto, Japan) equipped with a LC-10AD pump, SPD-10AV UV detector, SCL-10A $\mathrm{V}_{\mathrm{VP}}$ system controller, DGU-14A degasser, CTO-10AS $\mathrm{VP}_{\mathrm{vP}}$ column oven, and Rheodyne 7125 valve with a $20 \mu \mathrm{L}$ loop. The detector was set at $254 \mathrm{~nm}$ and peak areas were integrated automatically by Shimadzu Class VP V 6.14 software. The column used was a RP-C18A Merck (150 x $4.6 \mathrm{~mm}-5 \mu \mathrm{m})$. The mobile phase constituted acetonitrile:methanol:1 $\mathrm{M}$ perchloric acid:water $(33: 6: 1: 87, \mathrm{v} / \mathrm{v} / \mathrm{v} / \mathrm{v})$. The flow rate was $1.0 \mathrm{~mL} \mathrm{~min}^{-1}$. This quantitation method was previously validated according to the ICH guideline. ${ }^{9,16}$

A potentiometer (330i, WTW, Germany) was used to determine the $\mathrm{pH}$ of all solutions. Tablet hardness was measured on an OFF Tec hardness tester (Galileo, Brazil). The ultrasonic bath used for deaeration was a model USC (Unique, Brazil) and the centrifuge was a Laboezentrifugen 2-15 (Sigma, Germany).

\section{Development and validation of the dissolution test}

According to the USP recommendations, the solubility and stability of PQ were determined in 3 different dissolution media, as follows: 0.1 M hydrochloric acid ( $\mathrm{pH} 1.2$ ); water ( $\mathrm{pH} 4.2$ ), and 0.05 $\mathrm{M}$ phosphate buffer ( $\mathrm{pH} 7.4) .{ }^{13}$ Solubility was assessed taking into account the assurance of sink conditions, defined as a volume of medium at least 3 times that required in order to obtain a saturated solution of drug substance. ${ }^{13}$ Stability was evaluated for at least 24 $\mathrm{h}$ in all dissolution media. The solutions were kept at $37^{\circ} \mathrm{C}$ during the test period, and subsequently peak area and degradation product formation was verified by HPLC using a previously validated method. ${ }^{9}$

For dissolution tests, $900 \mathrm{~mL}$ of each medium were deaerated for 15 min prior to use and maintained at $37 \pm 0.5{ }^{\circ} \mathrm{C}$. The USP apparatuses, paddle and basket, were used at stirring speeds of 50 and $100 \mathrm{rpm}$, respectively. The 4 formulations were tested in each combination of dissolution media and apparatuses in 6 replicates.

The multiple time point dissolution was stopped at $24 \mathrm{~h}$. At specific time intervals, $10 \mathrm{~mL}$ samples were manually withdrawn from the dissolution medium and replaced with fresh medium to maintain a constant volume. These aliquots were immediately centrifuged and the measurements were performed by UV spectrophotometric methods.

Dissolution profiles $(n=6)$ were obtained by plotting percent drug release versus time. The equivalence between dissolution profiles of PQ tablets was evaluated using the similarity factor $(f 2)$ and dissolution efficiency (DE).

The similarity factor was introduced by Moore and Flanner, in $1996,{ }^{18}$ and is defined as follows:

$$
f 2=50 \log \left\{\left(1+\frac{1}{n} \sum_{t=1}^{n}\left(R_{t}-T_{t}\right)^{2}\right)^{-0,5} \times 100\right\}
$$

where $n$ is the number of dissolution sample times, and $R_{t}$ and $T_{t}$ are the individual percentages released at each time point, $t$, for the two dissolution profiles.

The DE concept is calculated from the area under the curve (AUC) of the dissolution profiles, being expressed as: ${ }^{19}$

$$
D E(\%)=\frac{\int_{0}^{T} Y \times d t}{Y_{100} \times T} \times 100
$$

where $Y$ is the percent drug release in function of time and $Y_{100}$ the percentage of the curve at maximum dissolution, over the time of total assay, $T$.

The calculations were performed for each individual vessel of the dissolution profiles. Analysis of variance (ANOVA) was applied to estimate significance of DE differences. In addition, for the evaluation of quantitative effects of the differences, Tukey-Kramer HSD (Honestly Significant Difference) method was used. The statistical analyses were performed using a 5\% level of significance.

After selection of the best test conditions, the repeatability (intra-day) and intermediate precision (inter-day) of the dissolution method was assessed. Repeatability was evaluated by assaying drug release from the F60P8 formulation in 6 vessels at predetermined times. The intermediate precision was assessed by comparing the repeatability assay on 3 different days. Results were expressed as relative standard deviation (R.S.D.) of the released percentage of PQ.

\section{Validation of the UV assaying methods}

A $200 \mu \mathrm{g} \mathrm{mL}^{-1}$ standard solution of PQ was obtained by dissolving $20 \mathrm{mg}$ of the reference standard in distilled water (for UV Method I) or in $0.1 \mathrm{M}$ hydrochloride acid (for UV Method II) placed into a $100 \mathrm{~mL}$ volumetric flask. Appropriate amounts of this solution were transferred to volumetric flasks and diluted with water or acid, yielding concentrations of $4,6,8,10$ and $12 \mu \mathrm{g} \mathrm{mL}^{-1}$. Calibration curves were constructed by plotting the concentration of PQ versus corresponding absorbance, and linearity was calculated by using an appropriate least-square regression program. The precision of the method was evaluated by performing 6 replicate injections of a PQ solution $\left(8 \mu \mathrm{g} \mathrm{mL}^{-1}\right)$ in distilled water (for UV Method I) or in 0.1 M hydrochloride acid (for UV Method II) on the same day (intra-day precision), and during 3 different days (inter-day precision). For accuracy evaluation, 10 tablets (F60P8) were weighed, finely powdered and a sample equivalent to $20 \mathrm{mg}$ of $\mathrm{PQ}$ transferred to a $100 \mathrm{~mL}$ volumetric flask and dissolved in ultrapure water, obtaining a $200 \mu \mathrm{g} \mathrm{mL}^{-1}$ PQ solution. Aliquots of $2 \mathrm{~mL}\left(200 \mu \mathrm{g} \mathrm{mL}^{-1}\right)$ were placed into $100 \mathrm{~mL}$ volumetric flasks containing 2, 3 and $4 \mathrm{~mL}$ of PQ standard solution $\left(200 \mu \mathrm{g} \mathrm{mL}^{-1}\right)$. Distilled water (UV method I) or 0.1 $\mathrm{M}$ hydrochloride acid (UV Method II) was added in order to obtain 
final concentrations of 8,10 and $12 \mu \mathrm{g} \mathrm{mL}^{-1}$. Percent recovery was determined in triplicate. The specificity of the method was evaluated by analyzing matrix tablets without PQ (placebo F60P8 formulation) under the selected dissolution conditions.

\section{RESULTS AND DISCUSSION}

The selection of media composition for dissolution testing was based on the $\mathrm{pH}$ range from 1.2 to 7.5 for extended-release oral formulations. ${ }^{13}$ The media tested were $0.1 \mathrm{M}$ hydrochloric acid $\mathrm{pH}$ 1.2 , water $\mathrm{pH} 4.2$ and $0.05 \mathrm{M}$ phosphate buffer $\mathrm{pH}$ 7.4. The buffer solution and diluted acid are related to physiological conditions. ${ }^{20}$

Leeson $^{21}$ reported that water impairs the release of active ingredients from some products and therefore good dissolution in water indicates even better in vivo release. Moreover, as far as hydrophilic matrices are concerned, water may be a more discriminative medium than those more similar to gastrointestinal conditions. Aqueous medium can allow a better comprehension of matrices behavior, such as swelling, water uptake and erosion mechanisms. On the other hand, Noory and co-workers ${ }^{22}$ stated that water lacks a buffering capacity and thus the $\mathrm{pH}$ of the medium may change as the drug dissolves, altering sink conditions. However, in the present work, few changes in $\mathrm{pH}$ were verified in the aliquots of the dissolution profiles obtained in water medium, as evident in Figure 1. Therefore, loss of buffering capacity was not relevant. The relative standard deviation (R.S.D.) of the measurements were $<5 \%$ with $\mathrm{pH}$ values ranging from 4.2 to $4.9(\mathrm{pH} 4.65 \pm 0.23$ for $\mathrm{F} 30 \mathrm{P} 4 ; \mathrm{pH} 4.67 \pm 0.22$ for F30P8; $\mathrm{pH} 4.62$ \pm 0.16 for F60P4; $\mathrm{pH} 4.58 \pm 0.19$ for F60P8).

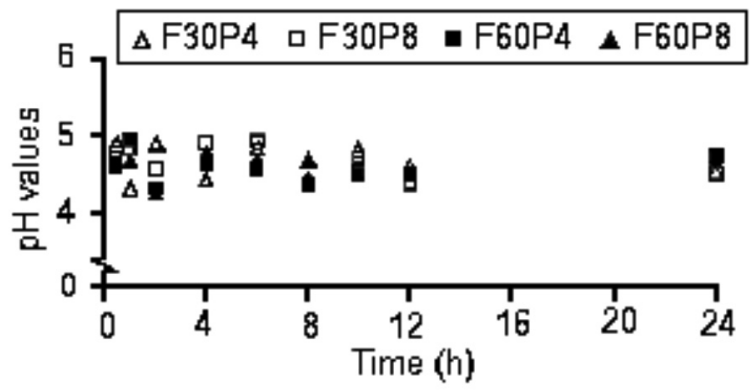

Figure 1. $p H$ measured in aliquots $(n=6)$ of the dissolution profiles of $P Q$ PEO matrix tablets using aqueous medium and paddle apparatus at $50 \mathrm{rpm}$

Although not expected in terms of a prolonged release, $0.1 \mathrm{M}$ hydrochloride acid is also a medium that correlates well with in vivo performance, since hydrophilic matrices may remain for a long period in acid conditions. The polyethylene oxide polymer making up the hydrophilic matrices, swells to a greater extent and tends to form a stronger gel upon hydration, which is bioadhesive and thus can prolong the permanence of the tablet in the stomach. ${ }^{11}$

During the selection of the medium, the solubility characteristics of the individual active ingredient must be considered. The evaluation of PQ solubility confirmed that sink conditions are obeyed in acid, basic and aqueous media. The representations of drug dissolved in $0.1 \mathrm{M}$ hydrochloride acid, water and $0.05 \mathrm{M}$ phosphate buffer during the test period are shown in Figure 2. The PQ showed stability in acid and aqueous media, and instability in phosphate buffer (approximately $15 \%$ decay in drug assay). According to the literature, the acceptable range of solution stability is $98-102 \% .{ }^{23}$ In fact, the HPLC analysis showed the presence of an additional peak, probably related to a degradation product of $\mathrm{PQ}$, after analysis of $0.05 \mathrm{M}$ phosphate buffer samples (Figure 3). Consequently, phosphate buffer cannot be considered an ideal medium, whereas acid and water media were selected for further studies.

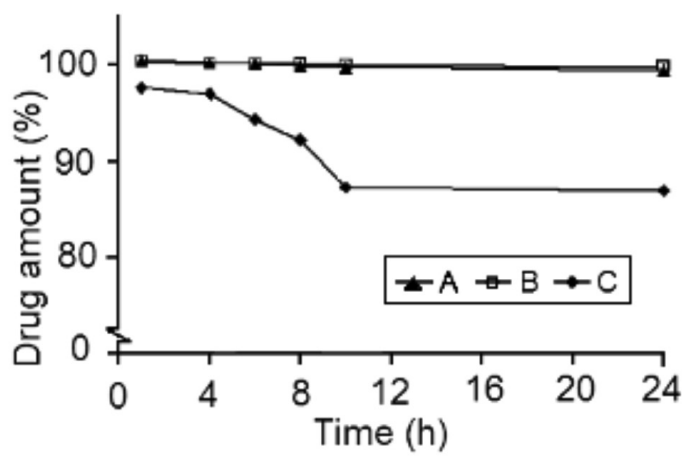

Figure 2. $P Q$ stability profiles in different media assessed by HPLC: (A) $P Q$ solution in $0.1 \mathrm{M}$ hydrochloride acid; (B) $P Q$ solution in aqueous medium; (C) $P Q$ solution in $0.05 \mathrm{M}$ phosphate buffer. All solutions had a concentration of $54 \mathrm{mg} \mathrm{mL^{-1 }}$

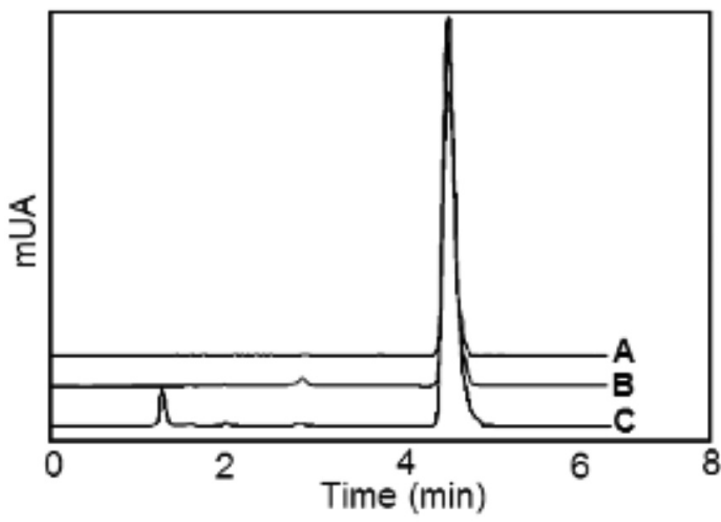

Figure 3. Chromatograms obtained in the stability study at $24 h:$ (A) $P Q$ solution in $0.1 M$ hydrochloride acid; (B) $P Q$ solution in aqueous medium; (C) $P Q$ solution in phosphate buffer. All solutions had a concentration of $54 \mathrm{mg} \mathrm{mL}^{-1}$

In order to employ the spectrophotometric method for drug assay during dissolution in both selected media, it was validated with results given in Table 2. Standard solutions $\left(10 \mu \mathrm{g} \mathrm{mL}^{-1}\right)$ were scanned and the UV spectrum showed two maximum absorbances for PQ occurring at 205 and $260 \mathrm{~nm}$ for UV method I (aqueous) and at 224 and $282 \mathrm{~nm}$ for method II (acid). No interference from the sample excipients were observed at these detection wavelengths. Therefore, 260 and $224 \mathrm{~nm}$ were selected as the most appropriate wavelengths for analyzing PQ with suitable sensitivity. The methods were linear in the 4-12 $\mu \mathrm{g} \mathrm{mL}^{-1}$ range following Beer's law. The least square regression data showed an excellent correlation coefficient $\left(\mathrm{R}^{2}>\right.$ 0.99 ) and y-intercepts that were not significantly different from zero at the $95 \%$ confidence level. Precision data indicated satisfactory intra-day and inter-day variability. Experimental values obtained in the recovery test indicated good agreement between both added and found amounts, confirming the accuracy of the methods.

Several types of dissolution apparatuses are described in the current USP $30^{13}$ where apparatuses 1 and 2 are the most widely used for oral solid dosage forms. The basket method (apparatus 1) is routinely used for capsules at agitation speeds of 50 and $100 \mathrm{rpm}$, while the paddle method (apparatus 2) is mainly used for tablets at 50 and $75 \mathrm{rpm}^{24}$

For a hydrophilic system that swells during dissolution, the USP apparatus 1 is usually not recommended because the matrix may clog the holes in the basket, impairing the hydrodynamics of the test. ${ }^{25}$ However, researchers observed that the basket apparatus at $100 \mathrm{rpm}$ allowed better contact of tablet with medium compared to the paddle apparatus, favoring drug dissolution. This effect was attributed to 
Table 2. Linearity, precision and accuracy data obtained in the validation process of UV spectrophotometric methods

\begin{tabular}{|c|c|c|c|c|c|c|}
\hline \multirow{3}{*}{ UV method } & \multirow{3}{*}{$\begin{array}{c}\text { Linearity } \\
\text { Correlation } \\
\text { coefficient }\end{array}$} & \multicolumn{2}{|c|}{ Precision } & \multicolumn{3}{|c|}{ Accuracy } \\
\hline & & \multirow{2}{*}{$\begin{array}{c}\text { Intra-day }\left(\mu \mathrm{g} \mathrm{mL}^{-1}\right) \\
(\text { R.S.D. }) \\
(\mathrm{n}=6)\end{array}$} & \multirow{2}{*}{$\begin{array}{c}\text { Inter-day }\left(\mu \mathrm{g} \mathrm{mL}^{-1}\right) \\
\text { (R.S.D.) } \\
(\mathrm{n}=3)\end{array}$} & \multicolumn{2}{|c|}{ Amount $\left(\mu \mathrm{g} \mathrm{mL}^{-1}\right)$} & \multirow{2}{*}{ Recovery $(\%$} \\
\hline & & & & Added & Found & \\
\hline I & 0.9999 & $\begin{array}{c}8.05 \pm 0.03 \\
(0.37 \%)\end{array}$ & $\begin{array}{c}8.07 \pm 0.14 \\
(1.73 \%)\end{array}$ & $\begin{array}{l}4.0 \\
6.0 \\
8.0\end{array}$ & $\begin{array}{l}3.99 \\
5.96 \\
7.99\end{array}$ & $\begin{array}{l}99.67 \pm 0.36 \\
99.39 \pm 1.04 \\
99.97 \pm 0.36\end{array}$ \\
\hline II & 0.9996 & $\begin{array}{c}8.17 \pm 0.01 \\
(0.12 \%)\end{array}$ & $\begin{array}{c}8.02 \pm 0.15 \\
\quad(1.87)\end{array}$ & $\begin{array}{l}4.0 \\
6.0 \\
8.0\end{array}$ & $\begin{array}{l}3.91 \\
5.86 \\
7.89\end{array}$ & $\begin{array}{l}97.83 \pm 0.09 \\
97.65 \pm 0.31 \\
98.57 \pm 1.53\end{array}$ \\
\hline
\end{tabular}

the full exposure of all surfaces of hydrophilic swelling tablets and appropriate hydrodynamics. ${ }^{26}$

The FDA recommends mild agitation conditions and, in particular, for the paddle apparatus, a stirring rate of $50 \mathrm{rpm}$ is suggested. ${ }^{27}$ In addition, most USP monographs considering extended-release tablets indicate this same stirring rate. Therefore $50 \mathrm{rpm}$ was chosen for the study. Moreover, the PQ immediate-release tablet monograph consists of $900 \mathrm{~mL} 0.1 \mathrm{M}$ hydrochloride acid with a USP apparatus 2 at $50 \mathrm{rpm}^{13}$ where this standard dissolution test method can be appropriate for both technologies.

Therefore, both apparatuses, basket at $100 \mathrm{rpm}$ and paddle at 50 rpm, were tested for each medium and formulation.

Visual observation of tablet behavior in the dissolution vessel is an important tool during the development of a method. Upon using the basket apparatus, a completely dissolved tablet was observed at the end of the test, whereas with the paddle apparatus, a residue of tablet

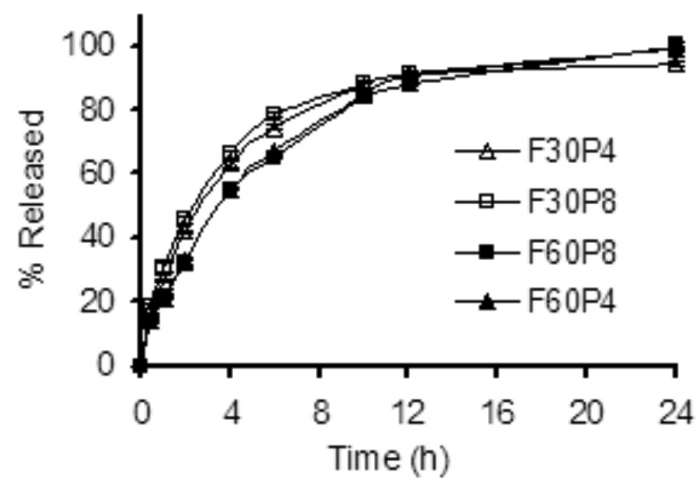

Figure 4. Dissolution profiles of $P Q / P E O$ matrix tablets ( $n=6$ tablets) using $0.1 \mathrm{M}$ hydrochloride acid medium and paddle apparatus at $50 \mathrm{rpm}$. S.D. values $<1.22 \%$

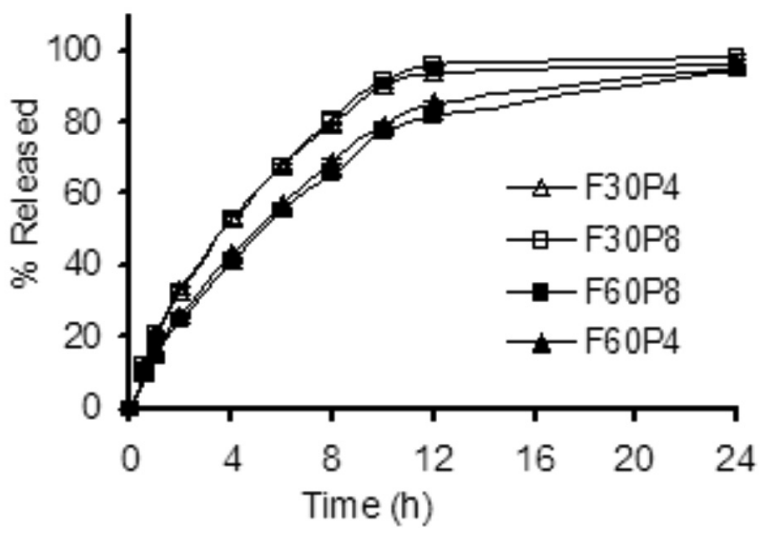

Figure 5. Dissolution profiles of $P Q / P E O$ matrix tablets ( $n=6$ tablets) using water medium and paddle apparatus at $50 \mathrm{rpm}$. S.D. values $<2.15 \%$ remained in the vials. Due to adhesive properties of the tablets, they tended to affix themselves to the bottom of the vials, hampering drug dissolution. This behavior has also been observed for non-modified release dosage forms and should be considered in the validation. ${ }^{28}$ In addition, the paddle apparatus at $50 \mathrm{rpm}$ may provide worse hydrodynamics in the dissolution vessel than the basket at $100 \mathrm{rpm}$. This less effective hydrodynamic is sometimes reported. ${ }^{29,30}$

A general increase in the dissolution rate and extent was observed for all formulations using the basket apparatus under strong agitation conditions (100 rpm) compared to the values obtained using the paddle at $50 \mathrm{rpm}$ (Figures 4, 5, 6 and 7). This result was confirmed by the increased dissolution efficiency values (Table 3 ).

Table 3 shows the following pattern of DE values: F30P8 > F30P4 > F60P4 > F60P8 and the results of ANOVA showed that all DE values differed significantly $(\mathrm{p}<0.05)$, but did not indicate which differences should be considered. In order to verify the significance

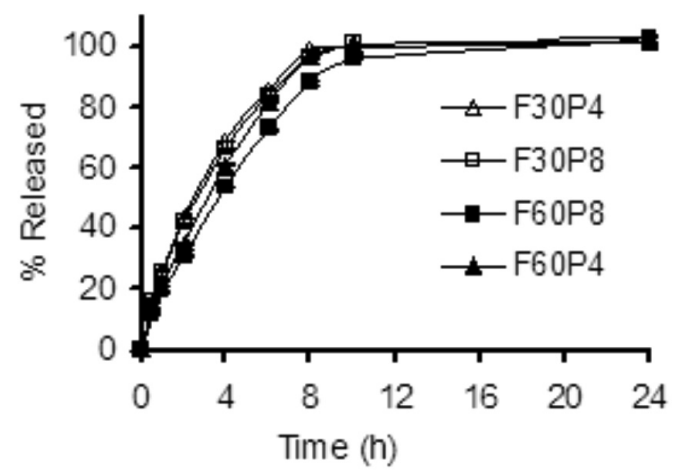

Figure 6. Dissolution profiles of $P Q / P E O$ matrix tablets ( $n=6$ tablets) using water medium and basket apparatus at $100 \mathrm{rpm}$. S.D. values $<0.74 \%$

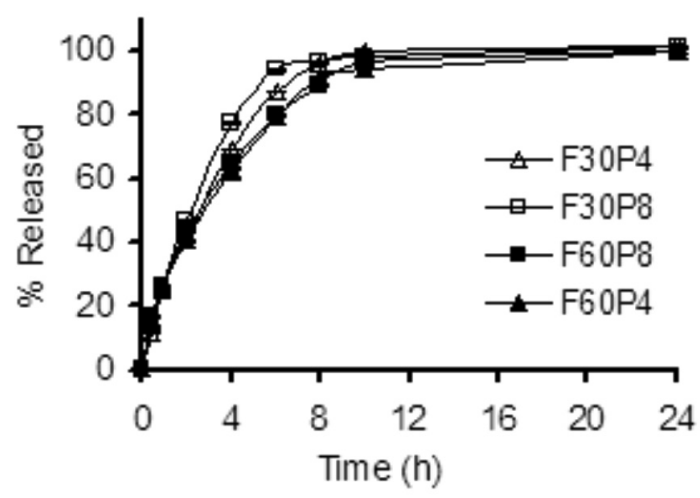

Figure 7. Dissolution profiles of $P Q / P E O$ matrix tablets ( $n=6$ tablets) using hydrochloride acid medium and basket apparatus at 100 rpm. S.D. values $<0.71 \%$ 
Table 3. Dissolution efficiency values of the F30P4, F30P8, F60P4 and F60P8 formulations obtained from dissolution tests assessed with different dissolution media, aqueous $\left(\mathrm{H}_{2} \mathrm{O}\right)$ and acid $(\mathrm{HCl})$, and apparatus, paddle and basket, at 50 and $100 \mathrm{rpm}$, respectively

\begin{tabular}{ccccc}
\hline \multirow{2}{*}{$\begin{array}{c}\text { Dissolution methods (apparatus, } \\
\text { rotation speed and medium) }\end{array}$} & F30P4 & \multicolumn{3}{c}{ Dissolution efficiency $(\mathrm{n}=6)$} \\
\cline { 2 - 5 } & $78.40(0.69)$ & $82.49(0.44)$ & F60P4 & F60P8 \\
\hline Paddle, $50 \mathrm{rpm}, \mathrm{HCl}$ & $77.79(0.86)$ & $80.82(0.82)$ & $71.66(0.52)$ & $76.63(0.41)$ \\
Paddle, $50 \mathrm{rpm}, \mathrm{H}_{2} \mathrm{O}$ & $87.18(0.15)$ & $88.44(0.16)$ & $86.45(0.34)$ & $69.48(0.77)$ \\
Basket, $100 \mathrm{rpm}, \mathrm{H}_{2} \mathrm{O}$ & $87.49(0.17)$ & $88.51(0.20)$ & $84.63(0.39)$ & $82.37(0.14)$ \\
Basket, $100 \mathrm{rpm}, \mathrm{HCl}$ & & & $83.76(0.38)$ \\
\hline
\end{tabular}

an parenthesis, relative standard deviation in percentage (R.S.D. \%); $\mathrm{n}$ is the number of measurements considering each vessel of the dissolution test.

Table 4. Pairwise comparison between formulations by Tukey-Kramer test, indicating the differences between mean dissolution efficiencies values of the formulations obtained from dissolution tests assessed with two dissolution media, aqueous $\left(\mathrm{H}_{2} \mathrm{O}\right)$ and acid $(\mathrm{HCl})$, and two apparatus, paddle and basket, at 50 and $100 \mathrm{rpm}$, respectively

\begin{tabular}{|c|c|c|c|c|}
\hline \multirow[t]{2}{*}{ Comparison $^{\mathrm{a}}$} & \multicolumn{2}{|c|}{ Paddle apparatus at $50 \mathrm{rpm}^{\mathrm{b}}$} & \multicolumn{2}{|c|}{ Basket apparatus at $100 \mathrm{rpm}^{\mathrm{b}}$} \\
\hline & $\mathrm{HCl}$ medium & $\mathrm{H}_{2} \mathrm{O}$ medium & $\mathrm{HCl}$ medium & $\mathrm{H}_{2} \mathrm{O}$ medium \\
\hline F30P4 x F30P8 & $-4.09(-4.69,-3.49)$ & $-3.02(-3.94,-2.11)$ & $-1.02(-1.42,-0.63)$ & $-1.25(-1.55,-0.96)$ \\
\hline F30P4 x F60P8 & $1.77(1.17,2.37)$ & $8.31(7.39,9.23)$ & $-3.74(-4.13,-3.34)$ & $4.81(4.51,5.11)$ \\
\hline F30P4 x F60P4 & $1.02(0.41,1.62)$ & $6.13(5.21,7.05)$ & $-2.86(-3.26,-2.47)$ & $0.72(0.42,1.02)$ \\
\hline F30P8 x F60P8 & $5.86(5.26,6.46)$ & $11.33(10.42,12.25)$ & $-4.76(-5.15,-4.36)$ & $6.06(5.76,6.36)$ \\
\hline F30P8 x F60P4 & $5.10(4.50,5.71)$ & $9.16(8.24,10.08)$ & $-3.88(-4.28,-3.49)$ & $1.98(1.68,2.28)$ \\
\hline F60P8 x F60P4 & $-0.76(-1.36,-0.15)$ & $-2.18(-3.1,-1.26)$ & $-0.87(-1.27,-0,48)$ & $-4.08(-4.38,-3.79)$ \\
\hline
\end{tabular}

${ }^{\mathrm{a}}$ All values were significantly different $(\mathrm{p}<0.05) .{ }^{\mathrm{b}}$ In parenthesis, the $95 \%$ confidence intervals.

of the differences, a pairwise comparison between formulations using the Tukey-Kramer test was performed (Table 4). The results obtained confirmed the existence of statistically significant differences between mean DE values of the formulations. Considering these results, all dissolution methods were therefore able to discriminate between formulations with varying amounts and molecular weights of polymer.

Nevertheless, the comparison of DE results addressed mainly the statistical differences rather than pharmaceutical differences, overestimating the discriminative power of the methods, as seen from the profiles in Figures 4 to 7 . The comparison was therefore complemented by $f 2$ analysis.

The $f 2$ values comparing the formulations under different dissolution test conditions were calculated from the means of percent released at each time point. The number of points was limited to no more than one after $85 \%$ dissolution, as recommended by the FDA. According to the FDA guidance, values of $f 2$ between 50 and 100 ensure equivalence of the two dissolution profiles. ${ }^{27}$ The dissolution profiles of F30P4, F30P8, F60P4 and F60P8 obtained in the hydrochloride medium (for both apparatuses and rotation speeds: paddle/50 $\mathrm{rpm}$ and basket/100 rpm) were considered equivalent to each other as shown in Table 5. On the other hand, in aqueous medium, using a paddle at $50 \mathrm{rpm}$, the F60P8 formulation was not considered similar to $\mathrm{F} 30 \mathrm{P} 4$ or F30P8. In addition, in aqueous medium, using a basket at $100 \mathrm{rpm}$, the F60P8 formulation was not equivalent to the F30P4. These results demonstrate that water medium was more discriminative than acid medium, since the aqueous medium distinguished variations in the matrix tablet compositions, as differences in percentage and molecular weight of the polymer. Besides its discriminative ability, water is a simple and convenient medium.

Considering the discriminative power of the water medium and the general increase in the dissolution rate and extent observed for all formulations upon using the basket apparatus at $100 \mathrm{rpm}$, this dissolution condition was selected..$^{31}$ Three time-points were specified for the
Table 5. $f 2$ values comparing the formulation in different dissolution tests using two dissolution media, aqueous $\left(\mathrm{H}_{2} \mathrm{O}\right)$ and acid $(\mathrm{HCl})$, and two apparatus, paddle and basket, at 50 and $100 \mathrm{rpm}$, respectively

\begin{tabular}{lcccc}
\hline \multirow{2}{*}{ Comparison } & \multicolumn{2}{c}{ Paddle at $50 \mathrm{rpm}$} & \multicolumn{2}{c}{ Basket at $100 \mathrm{rpm}$} \\
\cline { 2 - 5 } & $\mathrm{HCl}$ & $\mathrm{H}_{2} \mathrm{O}$ & $\mathrm{HCl}$ & $\mathrm{H}_{2} \mathrm{O}$ \\
\hline F30P4 x F30P8 & 74.52 & 92.96 & 64.96 & 82.50 \\
F30P4 x F60P8 & 57.73 & $48.66^{*}$ & 64.45 & $47.36^{*}$ \\
F30P4 x F60P4 & 59.20 & 53.30 & 64.98 & 62.42 \\
F30P8 x F60P8 & 50.44 & $47.48^{*}$ & 53.74 & 51.28 \\
F30P8 x F60P4 & 51.41 & 51.94 & 52.17 & 69.05 \\
F60P8 x F60P4 & 92.70 & 80.74 & 83.79 & 59.69 \\
\hline
\end{tabular}

* Values showing the difference between dissolution profiles $(f 2<50)$.

dissolution test. ${ }^{13}$ The first point, at $1 \mathrm{~h}$, was included to ensure that the product did not show excessive early release (dose dumping). At $1 \mathrm{~h}$, an amount of between 15 and $30 \%$ should be released. In order to define the release profile of the product, a middle time-point, 4 $\mathrm{h}$, was selected allowing for an amount released of between 50 and $70 \%$. The final time point of $8 \mathrm{~h}$ was chosen considering that no less than $80 \%$ should be delivered within this time.

In order to conclude the validation of the proposed method, the dissolution method selected was assessed with respect to repeatability and intermediate precision. The formulation containing the greatest PEO amount and highest molecular weight (F60P8) was elected as the "worst case", due to its lower dissolution efficiency and greater tendency to fail the criteria specified for the three time-points. As evident in Table 6, the established criteria were fulfilled by the F60P8 formulation and the experimental values indicated satisfactorily low variability in data, with R.S.D. $<3 \%$. 
Table 6. Repeatability and intermediate precision data evaluated through relative standard deviation (R.S.D.) of the determination of released primaquine by the proposed method: $900 \mathrm{~mL}$ aqueous medium, basket apparatus, $100 \mathrm{rpm}$ stirring speed and times of 1,4 and $8 \mathrm{~h}$

\begin{tabular}{ccc}
\hline \multirow{2}{*}{ Time intervals } & \multicolumn{2}{c}{ Released percentage $(\%)^{\mathrm{a}}$} \\
\cline { 2 - 3 } & Repeatability $^{\mathrm{b}}$ & Intermediate precision $^{\mathrm{c}}$ \\
\hline $1 \mathrm{~h}$ & $18.82(1.97)$ & $19.23(2.06)$ \\
$4 \mathrm{~h}$ & $54.25(2.71)$ & $54.79(0.89)$ \\
$8 \mathrm{~h}$ & $87.30(2.39)$ & $87.10(1.49)$ \\
\hline
\end{tabular}

an parenthesis, relative standard deviation in percentage (R.S.D. \%); ${ }^{\mathrm{b}}$ mean of 6 tablets; ${ }^{3}$ days.

\section{CONCLUSION}

The formulations developed (F30P4, F30P8, F60P4, F60P8) containing 30 or $60 \%$ (w/w) polymer of two molecular weights ( $4 \mathrm{x}$ $10^{6}$ or $8 \times 10^{6} \mathrm{Da}$ ), did not exhibit marked differences between the dissolution profiles after visual analysis. This is related to the high aqueous solubility of $\mathrm{PQ}$, hampering the ability of the dissolution methods to discriminate between formulations.

The dissolution efficiency (DE) of formulations varied from 69 to $88 \%$ in different medium and apparatuses and allowed differentiating formulations with respect to polymer content and molecular weight. The comparison was supplemented by similarity factor $(f 2)$ analysis which addresses pharmaceutical differences rather than statistical differences. The F60P8 formula had the worst DE (69.48\%) and the $f 2$ analysis showed that the F60P8 formulation differed to F30P4 and F30P8, in aqueous medium using a basket and a paddle, respectively, indicating that water was a more discriminative medium.

The cumulative percentage of released drug at 1,4 and $8 \mathrm{~h}$ obtained using the basket apparatus at $100 \mathrm{rpm}$ in $900 \mathrm{~mL}$ of water medium was considered the best dissolution test condition. The experimental condition proved to be simple, precise, specific, repeatable and discriminative and also guaranteed drug stability. Therefore, a dissolution method was successfully developed and validated for PQ matrix tablets.

\section{ACKNOWLEDGMENTS}

We would like to thank the Conselho Nacional de Desenvolvimento Científico e Tecnológico (CNPq-Brazil) for financial support as well as the Institute of Technology in Drugs - Fundação Oswaldo Cruz/ Far-Manguinhos.

\section{REFERENCES}

1. Vale, N.; Moreira, R.; Gomes, P.; Eur. J. Med. Chem. 2009, 44, 937.

2. Word Health Organization (WHO); World Malaria Report 2008, Geneva, 2008, http://www.who.int/malaria/publications/atoz/9789241563697/ en/index.html, accessed in April 2012.

3. Tracy, J. W.; Webster Jr., L. T. In Goodman \& Gilman's the pharmacological basis of therapeutics; 10 ${ }^{\text {th }}$ ed., McGraw-Hill: New York, 2001.
4. Baird, J. K.; Hoffman, S. L.; Clin. Infect. Dis. 2004, 39, 1336.

5. Sweetman, S. C.; Martindale: The Extra Pharmacopeia, $33^{\text {th }}$ ed., Royal Pharmaceutical Society: London, 2002.

6. Baird, J. K.; Rieckmann, K. H.; Trends Parasitol. 2003, 19, 115.

7. Al-Badr, A. A.; Prof. Drug Subst., Excip., Relat. Method. 2005, 32, 153.

8. Cruz, A. P.; Bertol, C. D.; Stulzer, H. K.; Murakami, F. S.; Costella, F. T.; Rocha, H. V. A.; Silva, M. A. S.; Pharm. Chem. J. 2008, 42, 413.

9. Cruz, A. P.; Bertol, C. D.; Murakami, F. S.; Silva M. A. S.; Lat. Am. J. Pharm. 2008, 27, 415.

10. Bertol, C. D.; Cruz, A. P.; Stulzer, H. K.; Murakami, F. S.; Silva, M. A. S.; J. Therm. Anal. Calorim. 2010, 102, 187.

11. Dhawan, S.; Varma, M.; Sinhá, V. R.; Pharm. Technol. 2005, May, 72.

12. Bertol, C. D.; Oliveira, P. R.; Kuminek, G.; Rauber, G. S.; Stulzer, H. K.; Silva, M. A. S.; Ann. Trop. Med. Parasitol. 2011, 105, 475.

13. The United States Pharmacopeia, $30^{\text {th }}$ ed., United States Pharmacopeial Convention: Rockville, 2007.

14. Menegola, J.; Steppe, M.; Schapoval, E. E. S.; Eur. J. Pharm. Biopharm. 2007, 67, 524.

15. Furlanetto, S.; Maestrelli, F., Orlandini, S., Pinzauti, S., Mura, P.; J. Pharm. Biomed. Anal. 2003, 32, 159.

16. International Conference on Harmonization ( $\mathrm{ICH})$; Guideline on the Validation of Analytical Procedures: Text and Methodology Q2 (R1), 2005.

17. Food and Drug Administration (FDA); Draft Guidance for Industry on Analytical Procedures and Methods Validation: Chemistry, Manufacturing, and Controls Documentation, Availability, Fed. Regist. 65 (169) 52776-52777, 2000.

18. Moore, J. W. H.; Flanner, H.; Pharm. Technol. 1996, $20,64$.

19. Khan, K. A.; J. Pharm. Pharmacol. 1975, 27, 48.

20. Lagace, M.; Gravelle, L.; Di Maso, M.; Mcclintock, S.; Dissol. Technol. 2004, February, 13.

21. Leeson, L. J.; Dissol. Technol. 2000, 7, 16.

22. Noory, C.; Tran, N.; Ouderkirk, L.; Brown, S.; Perry, J.; Lopez, J.; Colon, M.; Henry, K.; Roberg, J.; Nasir, S.; Shah, V.; Dissol. Technol. 1999, 6,6 .

23. Marques, M. R. C.; Brown, W.; Analytical 2002, 1, 48.

24. Food and Drug Administration (FDA); Guidance for Industry on Dissolution Testing of Immediate Release Solid Oral Dosage Forms, Availability, Fed. Regist. 62 (164) 44974-44975, 1997.

25. Jorgensen, E. D.; Bhagwat, D.; PSTT 1998, 1, 128.

26. Dürig, T.; Fassihi, R.; J. Controlled Release 2000, 67, 37.

27. Food and Drug Administration (FDA); Guidance for Industry: SUPACMR, Modified Release Solid Oral Dosage Forms; Scale-up and Post approval Changes for Chemistry, Manufacturing and Controls. 62 (193) 52138-52139, 1997.

28. Kuminek, G.; Stulzer, H. K.; Tagliari, M. K.; Oliveira, P. R.; Bernardi, L. S.; Rauber, G.; Quim. Nova 2012, 35, 207.

29. Galia, E.; Horton, J.; Dressman, J.; Pharm. Res. 1999, 16, 1871.

30. Bertocchi, P.; Antoniella, E.; Valvo, L.; Alimonti, S.; Memoli, A.; J. Pharm. Biomed. Anal. 2005, 37, 679.

31. Soares, M. F. L. R.; Soares Sobrinho, J. L.; Grangeiro Jr., S.; Silva, K. E. R.; Alves, L. D. S.; Rolim Neto, P. J.; Quim. Nova 2010, 33, 478. 